\title{
PRINCIPIO DEL ALCANCE COMUNITARIO EN LA VIDA DE LA COMUNIDAD CREYENTE
}

\author{
THE PRINCIPLE OF THE COMMUNAL SCOPE \\ IN THE LIFE OF THE FAITHFUL COMMUNITY
}

Mons. Dr. Miguel Antonio Barriola

\section{Resumen}

Según los "Hechos" de Lucas la comunidad eclesial no se basaba sólo en motivos sociales (clases) o psicológicos (simpatías), sino en la fe y sobre todo la Eucaristía. La comunión de fe engloba todos los planos de la vida humana.

Esta verdad y praxis es confirmada en las correcciones de S. Pablo a las divisiones sociales de la Iglesia de Corinto, presentes hasta en la celebración de la Eucaristía. Separatismo de clases no armoniza con la entrega de Cristo por todos. Sin embargo tales errores no autorizan una "huelga de Eucaristía".

Palabras clave: Koinonía - participación - fracción del pan - División - Comunión - Entrega de Cristo.

\section{Abstract}

According to the "Acts" of Luke, the ecclesiastic community bases not only in social motives (classes) or psychological (sympathies), but in faith and over all, in the Eucharisty. The communion in faith includes all dimensions of human life.

This truth and practice is confirmed by the Pauline corrections of social divisions in the Corinthian Church, even in the Eucharistic celebrations. Separations of classes do not harmonize with Christ's selfdelivery for all. However, such errors do not justify any "strike of Eucharisty".

Key words: Koinonía - participation - brod'sfraction - Division - Communion Christ's selfdelivery 


\section{Comunidad y moral en los Hechos} de los Apóstoles

El Señor Dios escogió a personas singulares (Abraham, David, etc.), pero siempre en vistas a formar "su pueblo". De modo que las relaciones con él nunca podrán adoptar un tinte individualista.

Igual entronque comunitario de la fe y la consiguiente práctica moral se imponen en la Definitiva Alianza y en la vida de la Iglesia cristiana, nuevo pueblo de Dios (I Ped 2, 9 - 10).

Tal es la existencia de las primeras comunidades, con sus aciertos, puestos de relieve, sobre todo, por los Hechos de los Apóstoles y también con sus yerros a corregir, según las severas intervenciones de Pablo.

\section{1 - Los "Sumarios" de Hechos 2,}

\section{$42-47 ; 4,32-37 ; 5,12-16^{1}$}

Las características de la primera Iglesia desarrollan la respuesta a la pregunta formulada

\footnotetext{
${ }^{1}$ El primero parece ser fuente de los demás, porque algunos de los temas allí tratados se presentan después en los otros dos. De ahí que algunos lo califiquen como "el sumario de los sumarios". Pese a que cada uno recibe su perfil propio $(2,42-47$ acentúa la vida de piedad; 4, 32-37 detalla más la comunidad de bienes -introduciendo el episodio de Ananías y Safira-; 5, 12-16 resalta la actividad taumatúrgica de los apóstoles), nos detendremos en el primero, ilustrándolo con las analogías y matices que ofrecen los otros dos. Pese a su brevedad contienen abundantes riquezas, que no podremos indagar a fondo.
}

por los oyentes de Pedro en Pentecostés: "Hermanos ¿qué debemos hacer?" (Hech 2, 37). Una inquietud que apunta directamente a la moral. Los cuadros que siguen responden en parte a la historia y también al ideal que el autor propone en ellos

Ahora bien, después del solemne ingreso a la comunidad, por medio la conversión y el bautismo $(2$, 38-41) de "alrededor de tres mil personas", introduce Lucas el primer panorama de la práctica ordinaria en las primeras comunidades.

\section{a) Catequesis constante}

En Hech 2, 42 se destaca la "perseverancia de todos en la enseñanza de los apóstoles".

Tal constancia enlaza con el núcleo primitivo $(1,14)$ y es reiterada en el v. 46. Se está indicando con ello que no basta con haber escuchado el primer anuncio misionero. En adelante se requiere un trabajo asiduo en comprenderlo siempre mejor, por medio de la explicación apostólica. En torno a ella han de permanecer unidos para toda la vida. $\mathrm{Ya}$ de aquí se desprenden consecuencias morales, tanto para los responsables de la comunidad, como para quienes son por ellos dirigidos. A la tarea de los apóstoles en su ministerio específico de testigos de Cristo, corresponde la firmeza de los creyentes en aceptar y seguir la enseñanza. Si los apóstoles permanecieran fieles, pero los 
creyentes se apartaran de la doctrina recibida, buscando en otro lado ideas tenidas por más actuales, romperían la unión que los une a los apóstoles $y$, al abandonarlos, se alejarían del mismo Jesús. Aunque la "doctrina de los Apóstoles" era todavía rudimentaria, sin las profundizaciones que ellos mismos irían llevando a cabo (ver: Hech 11, 15-16; toda la teología paulina, etc.), era normativa para la Iglesia. La obligación de enseñar en los maestros y la correlativa obediencia de los fieles encuentra aquí uno de sus fundamentos.

\section{b) La Koinonía}

El segundo aspecto, en el que todos se mantenían unidos, está indicado con un término genérico: "la comunión" (koinonía), palabra que figura una sola vez en los Hechos $^{2}$. Es difícil decidirse por un sentido concreto. Con todo, dado su parentesco con otras de igual raíz o con situaciones análogas en los restantes sumarios, se puede entender el vocablo impreciso como incluyendo todos los aspectos que,

\footnotetext{
2 En otros lugares del N.T. reviste estos sentidos: 1) la unión espiritual de los fieles con Dios (I Jn 1, 6), con Cristo (I Cor 1, 9; Filip 3, 10), con el Espíritu Santo (I Cor 13, 13; Filip 2, 1). 2) Poner a disposición de todos los bienes necesarios a la existencia terrenal (Hebr 13, 16). 3) La unión que resulta de la participación en la "sangre y cuerpo de Cristo" (I Cor 10, 16). 4) El gesto de solidaridad concretizado en la colecta de las iglesias (Rom 15, 26; II Cor 8, 4; 9, 13).
}

ya antes y después, el mismo Lucas va determinando.

Germinalmente se da casi como una unidad local $(1,14 ; 2,1)$, que enseguida se vuelve social $y$, dado que se funda en la fe (se repite el apelativo "creyentes": 2, 44; 4, 32; 5, 14), se vuelve espiritual bajo diversas manifestaciones: la unidad cultual, de los ánimos que, casi necesariamente, desemboca en la comunidad de bienes. Se insinúa desde ahora cómo la unidad y su factor amalgamante, la misma fe, alertan contra cualquier tipo de disensión o diferencia proveniente, por ejemplo, de la posición social acomodada $\mathrm{O}$ indigente. A la enseñanza de los Apóstoles, en cuanto anuncio, corresponde la unión fraterna como respuesta vivida. El Evangelio no es genuino, sin una repercusión comunitaria en la existencia cristiana.

\section{c) La Eucaristía}

En tercer lugar se hace referencia a elementos superiores a la mera buena voluntad, que pudieran aportar los componentes de la comunidad: la "fracción de pan" y "las oraciones". La primera es un término técnico de Lucas, que se refiere a la celebración de la Eucaristía $^{3}$. Los cristianos, pues, no

${ }^{3}$ El verbo kláo (romper), usado en 2, 46, aparece unas 15 veces en el N. T., especialmente en Lucas y casi la mitad de ellas en relación con la Eucaristía. En 2, 42 vemos el sustantivo klásis, que figura sólo otra vez más en el relato de Emaús, 
basaban su comunión sólo en sentimientos humanos, sino que, en sus reuniones cultuales confesaban que no podían mantenerse con sólo sus fuerzas naturales. Siempre alimentaban el vigor de su cohesión en la Mesa de Señor y la oración. Hablaban con Dios antes de dirigirse a los hombres. Podían encarar los problemas de la vida, porque primeramente se medían con Dios ${ }^{4}$.

Insistirá otra vez el autor sobre este rasgo en el v. 46, donde parece que se va perfilando como el distintivo de la Iglesia cristiana, ya que se dirá que, en sus comienzos, frecuentaban todavía "todos los días el templo", pero además: "partían el pan en sus casas y comían juntos con alegría y sencillez de corazón". Habiendo ya apuntado la semejanza de este pasaje con Lc 24, 25-30 teniendo en cuenta Hech 20, 7 y I

precedido justamente de la exégesis escriturística con que el Resucitado fue abriendo los ojos de Cleofás y su compañero (LC 24, 25-30). No cabe duda de que se trata de un anticipo de las características propias de las comunidades creyentes de Hechos, "Constantes en escuchar la enseñanza de los apóstoles" y en "el partir del pan" (Hech 2, 42).

4 Esta perseverancia en la oración (tema preferido de Lucas) es confirmada en el recurso constante a ella: para decisiones fundamentales (elección de Matías: 1, 24; de los siete servidores helenistas: 6, 6; de los presbíteros en las comunidades locales: 14 , 23 , etc.); a fin de ser fieles durante las persecuciones (contra los apóstoles: 4, 2331; contra Pedro: 12, 5. 12); como preparación para recibir los dones divinos (el Espíritu Santo: 1, 14; alcanzar el conocimiento de las disposiciones de Dios: 4, 23-30; 10, 9. 30; 11, 5, etc.).

${ }^{5}$ Ver: nota 3.
Cor $11,17-34$, es obvio que se trata de comidas fraternas que se enlazaban con las que los apóstoles tuvieron con Jesús $y_{\text {, en modo }}$ particular con la de la Ultima Cena. En efecto, no se podría entender que el autor se preocupara en decir que los fieles "perseveraban" en servirse una comida ordinaria. Semejante constancia no es una señal distintiva de la vida cristiana. Estamos, pues, ante una mesa solidaria, que ofrecía a los miembros más pobres de la comunidad la posibilidad de beneficiarse de su ración cotidiana de alimentos, gesto que se desprendía de la fe y el amor irradiados por la entrega de Cristo a todos los hombres.

Fraternidad, participación y celebración de la fe estaban fusionadas en la única comida. En consecuencia, el culto no podía verse desligado de la moral.

Se enfatiza también la unidad de alma, no el mero encontrarse todos juntos. Omothymadón, en efecto, indica igualdad en el thymos, el ánimo.

\section{d) Comunidad de bienes}

Como resultado de lo expuesto, se llega a una koinonía concretizada en el "tener todo en común" (ápanta koiná: v. 44). El verso siguiente determina más, precisando que se trata de las "propiedades" (ktémata significa bienes inmuebles) y "sustancias" (hypárxeis indica posesiones en general). Todo esto 
era "vendido", distribuyendo lo recabado en dinero a medida de las necesidades, por intermedio de los apóstoles (como surge de 4, 15).

En realidad no se quiere dar a entender que no había propiedad privada, sino que "nadie consideraba suyo nada de lo que tenían", según se especifica en $4,32^{6}$. Por tanto, se sobreentiende que los cristianos no abandonaban sus propiedades por principio, sino que no se consideraban patrones absolutos de las mismas, poniéndolas a disposición según se presentaran las necesidades de los hermanos; "comprando como sin poseer nada" (I Cor 7, 30).

La generalidad de 2, 45 recibe también una nueva determinación en 4, 34, donde se especifica que "los que poseían tierras o casas las vendían". Por consiguiente, los que vendían en 2, 45 eran solamente terratenientes y propietarios de inmuebles.

De igual modo, por parte de los beneficiados se precisa que, recibían "según la necesidad de cada uno" $(2,45$ y 4, 35), con lo que se insinúa que no todos gozaban en la vida de iguales recursos, suponiendo asimismo que cada uno seguía ganándose la vida, poseyendo y administrando sus bienes.

Es posible todavía ajustar más la visión, si se tiene en cuenta la totalidad de información, que ofrece

\footnotetext{
${ }^{6}$ Se emplea el verbo hypárjo, muy frecuente en Lucas y que significa la idea de posesión.
}

Lucas. No se puede sacar la conclusión de que, aún entre los propietarios, todo el mundo se desprendía de sus casas. Hay noticias que contradicen semejante supuesto. En efecto, por 2, 46 y en 5, 42 sabemos que la fracción del pan y otras reuniones comunitarias se llevaban a cabo "en las casas". También se informa en 12, 12 que María, la madre de Juan Marcos, era la dueña de la casa, en la que se juntaba la asamblea. Felipe, uno de los siete, posee también su casa (21, 8).

Por ende, sería iluso imaginar un desprendimiento generalizado, a la manera de los miembros de una orden mendicante, ya que si todos se deshacían de la morada donde habitaban, se habría logrado por algún tiempo un estado de prosperidad con el resultado de lo vendido, pero se arrastraría no menos la pesada carga de tener que encontrar techo para la masa de los cristianos. Se deberá, entonces, entender que, por lo común, se seguía habitando en la propia casa y que algunos de los que disponían de otras propiedades, que les rendían ganancias, las vendían con el fin de ayudar a los indigentes.

Tal interpretación se confirma con el ejemplo, que sigue inmediatamente después del segundo sumario $(4,36)$. El autor, en efecto, destaca la generosidad de Bernabé: "Poseyendo un campo, lo vendió, aportó el dinero y lo depositó a los pies de los apóstoles". Es raro que Lucas se repita casi 
literalmente; y llama igualmente la atención que use para elogiar a sBernabé un modo de actuar que sería habitual en todos los cristianos, porque lo que es común no tiene por qué ser resaltado expresamente en uno. Se sigue que está dando a entender que un paso así era más bien raro, insinuando, que no se ha de tomar al pie de la letra aquel "todos" de 2, 42 y 4, 34.

Esta matización encuentra un nuevo apoyo en el caso de Ananías y Safira (5, 1-11). Cometieron una falta, al no entregar íntegra la cantidad obtenida, pero no porque estuvieran obligados a total desprendimiento, ya que el precio de la venta seguía estando a disposición de la pareja. En efecto, Pedro no los reprende por haber retenido algo, ya que nada habría pasado en caso que no hubiesen vendido y aún después de la venta, hubieran usado según su propio criterio el dinero $(5,4)$. El fraude consistió en haber intentado engañar a Dios, su Espíritu y los apóstoles $(5,4.9)$, haciéndoles creer que habían aportado la suma entera de lo conseguido.

De todo esto se desprende que la propiedad privada no era considerada como pecado contra la koinonía. Era corrientemente admitida, aunque no para "uso y abuso", sino teniendo en la mira modos libres, no impuestos por regla alguna, de salir al encuentro de los necesitados en la Iglesia. Lo cual está de acuerdo con la visión de Pablo, que considera la koinonía, no como "comunismo forzado", aunque sí como imperativo de la caridad, indicando que "sobre toda propiedad privada grava una "hipoteca social»" (Juan Pablo II, 1982, p. 397). Sirva de ejemplo II Cor 8, 13-14:

No se trata de aliviar a otros pasando vosotros estrecheces, sino que, por exigencia de la igualdad, en el momento actual vuestra abundancia remedie la falta que ellos tienen, para que un día la abundancia de ellos remedie vuestra falta, y así haya igualdad.

Si las advertencias anteriores nos llaman a prudencia en cuanto a la generalización de esta actitud, con todo, otros apuntes de Lucas nos invitan a no minimizar la generosidad de los primeros cristianos. Hech 6, 1 informa que muy tempranamente había sido organizada una "distribución diaria de los alimentos" especialmente en favor de las viudas. Experimentaron enseguida que se imponía una reorganización de tal servicio, para evitar fricciones entre "hebreos" y "helenistas". La existencia de una ayuda de este género constituía necesariamente una carga, que no podía ser llevada adelante sin una caridad generosa y desinteresada.

De hecho, la comunidad de Jerusalén no tardó en conocer la indigencia y tuvo que recibir la ayuda de otras Iglesias, según informa el mismo Lucas $(11,29-30)$ y también Pablo (Gál 2, 10; I Cor 16,1-4; II Cor 8-9; Rom 15, 25-28).

Sin embargo, aquellos intentos, que no fueron del todo 
coronados por buenos resultados, transmiten, así y todo, un mensaje permanente. Enseñan que la moral cristiana es incompatible con un apego egoísta a las riquezas de este mundo, que la comunión de fe engloba todos los planos de la vida humana, y que es ilusorio pretender entrar en comunión con Jesucristo, sin hacer partícipes de los bienes propios a los "necesitados". La comunión cristiana no admite divisiones entre culto y vida, entre cristianosacomodadosymenesterosos (Ver también: Sant 2, 1-7).

Muy a tono, pues, con la teología de Lucas, esta koinonía señala la postura cristiana ante la riqueza. Se abandonan los propios bienes, no por el deseo de ser pobre, a la manera de un filósofo estoico o cínico. Y mucho menos como un revolucionario, comprometido en una lucha de pobres contra ricos, para imponer una justicia social. Tan es así que en Hechos no se encuentra una sola vez la palabra "pobre" y la única vez en que se habla de "indigentes" $(4,34)$ es para negar que los hubiese en la comunidad de Jerusalén. No interesa tanto la pobreza, cuanto que no haya pobres entre los hermanos. La meta perseguida consiste en que cada uno acceda a satisfacer sus necesidades vitales y que los que se vean privados de esa posibilidad la encuentren en la generosidad de los demás. Para poner por obra tal entrega, los creyentes han de sacar inspiración y fuerzas de la fe y de la misma vida compartida entre todos.
Existieron, se dan en la actualidad y seguirán apareciendo sociedades filantrópicas. Pero la Iglesia no es esto en primer lugar. Es un organismo vivo, que se nutre de Dios en la oración y en el "pan partido" y "compartido" de la Eucaristía. Con todo, iría en contra de la fuerza expansiva del amor, el que no se extendiera también hasta estas consecuencias de orden económico y necesidades primordiales.

He ahí un reto urgente para nuestros días, en que los cristianos del hemisferio norte no saben qué hacer con el dinero, cuando inmensas mayorías de los del sur a duras penas pueden sobrevivir.

\section{e) Comunión de almas}

$\mathrm{Si}$ bien encontramos expresiones greco-latinas bastante similares a la descripción lucana de la koinonía de los cristianos $^{7}$, sobre

\footnotetext{
7 Aristóteles describe la amistad como "un alma inhabitando en dos cuerpos" (Aristóteles, 1995, IX, 8:1168 b, 8). Diógenes Laercio: "Son comunes (koiná) las cosas de los amigos y la amistad es igualdad" (Diógenes Laercio, 1945, VIII, 10). Sin embargo, griegos y romanos estarían dispuestos a compartir los bienes dentro de un selecto círculo, integrado por personas iguales en nobleza, a lo más concederían préstamos, pero en ningún caso apreciarían a los indigentes. Los cristianos han de amar a los "inferiores", como el Padre, que envió a su Hijo, en ayuda nuestra, aún cuando todos éramos pecadores (Rom 5,8 ). Los griegos no se dignaban conceder su amor a personas 0 cosas que no consideraran a su altura o que no fueran bellas. Además, aquellas comunidades pitagóricas (al igual que las
} 
todo para ponderar la estrecha unión que produce la amistad, es notorio que Lucas nunca caracterice a los cristianos como "amigos", siendo así que echa mano del término en otros contextos $(10,24 ; 19,31 ; 27,3)$. Ni siquiera los llama "hermanos". Le basta presentarlos como "creyentes" $(2,44 ; 4,32 ; 5,14)$.

Vale decir que la fuente de la "comunión" dimana de la fe, que los une con Cristo y entre sí, no tanto por pertenecer a una misma clase social, ideología política o por lazos de simpatía y cercanía. Está claro que será siempre bienvenido todo factor que contribuya a afianzar el espíritu comunitario, pero, por más que haya algo de idealización en los números de personas, que se iban agregando al núcleo apostólico, según va informando Lucas $^{8}$, la descripción de "la multitud de los creyentes como

esenias, en Israel) fueron muy cerradas, suponiendo ciertas características, que llegarían a ser autodestructivas. Tenían que retirarse de la sociedad, a fin de que todo funcionara armónicamente. Esto las volvía exclusivistas, apartadas, pequeñas numéricamente e intolerantes con los de fuera. En Hechos no encontramos ninguna "Regla de la Comunidad", como en Qumrán. Por lo demás, el retraimiento es opuesto al espíritu misionero y expansivo de los cristianos. Estos actúan movidos por el amor y dirigidos por el Espíritu Santo, para que realicen lo que sea apropiado en cada situación.

8 "Tres mil": 2, 41; "cada día el Señor iba acrecentando la comunidad": ibid., v. 47; "Aumentaba cada vez más el número de los que creían en el Señor, tanto hombres como mujeres": 4, 4; "Cinco mil"; 5, 14; "como el número de los discípulos aumentaba...": 6 , 1.7; "Toda la población de Lida y de la llanura de Sarón: 9,35; “Toda Jafa": 9, 42. una sola alma y un solo corazón" (4, 1) no puede ser entendida distributivamente, aplicando tales características sólo a los pequeños grupos domésticos, por separado. $Y$, si bien, junto con las pinceladas idílicas, Lucas notifica también honestamente los roces y diferencias que surgieron en aquella "edad de oro" eclesial", la fe común, bajo la guía de los apóstoles, los iba haciendo superar el encastillamiento en corrillos, donde la tonalidad reinante surgiría sólo de factores sicosociales. De hecho no es necesario que una agrupación de bautizados constituya una comunidad humanamente compacta, para que se pueda "partir el pan", con todas las consecuencias muy concretas que de allí dimanan. Aunque sí es necesario que se esfuercen para dar origen a una comunidad viva y cada vez más unida ${ }^{10}$.

Lo cual significa que no son las afinidades selectivas, ideológicas, culturales o conexiones socialmente humanas, las que nos facultan a entrar en comunión, sino que el

9 Ananías y Safira (5, 1-11); "helenistas y hebreos" (6, 1-7); resquemores ante el bautismo de Cornelio $(11,3)$; controversia sobre la circuncisión de los cristianos procedentes del paganismo (15, 1-35); desinteligencia entre Pablo, y Bernabé a causa de Marcos (ibid., vv. 36-40).

10 Será la preocupación fundamental de Pablo ante la Iglesia de Corinto, asediada por tendencias separatistas. No la declarará desahuciada, ni les prohibirá celebrar la "Cena del Señor", sino que mostrará constantemente que los lazos de unidad son siempre más fuertes que los motivos de separación, que estarían en total disonancia con la única fe en Cristo. 


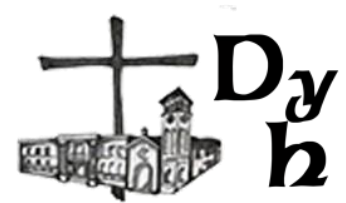

Señor glorificado es quien convoca y confirma la cohesión eclesial, interpelando a sus miembros a que superen sin desmayo el natural egoísmo hasta constituir verdaderamente una familia.

La pequeña comunidad, que no cultivase ni apreciase la macrounidad, sería del todo inoperante para paliar una crisis en el sentimiento de pertenencia a la totalidad. Grupos de este tipo pueden existir dentro de la Iglesia sólo en el supuesto de que haya una sana conciencia de koinonía, o sea una vivencia concreta de estar en conexión con el todo, de lo contrario perecen.

Por lo mismo, el v. 33 del segundo sumario $(4,32-37)$, que parece interrumpir poco lógicamente la descripción, con que se reitera la "comunión de bienes" (vv. 32 y 34), lejos de ser una idea poco afín o intrusa, constituye más bien la realidad profunda de donde nace esa apertura a todos: "Los apóstoles daban testimonio con mucho poder de la resurrección del Señor Jesús y gozaban de gran estima". Ya que es el hecho pascual, propiamente, el que da comienzo a un modo diverso de vivir, tanto para Jesús como para la humanidad.

En los Hechos de los Apóstoles nunca nos encontramos con el término agapáo o agápe. En su lugar está koinonía y las expresiones a ella equivalentes. Lo podemos corroborar con lugares semejantes en Pablo: "Teniendo la misma caridad (agápen), unánimes (sýmpsyjoi)" (Filip 2, 2) ${ }^{11}$. El mismo Pablo, en cierta manera resumió toda la vocación cristiana en la koinonía: "Fiel es Dios, por el cual fuisteis llamados a la comunión (eis koinonían) de su Hijo Jesucristo nuestro Señor" (I Cor 1, 9).

Pero esta koinonía alcanza su ápice singular en la "fracción del pan":

El cáliz de bendición que bendecimos, ¿no es acaso la koinonía de la sangre de Cristo? El pan que partimos, ¿no es acaso la koinonía del cuerpo de Cristo? Dado que hay un pan, muchos somos un solo cuerpo, todos los que de un mismo pan participamos (I Cor 10, 16).

Estos enlaces tan estrechos, en cuanto a tema y el vocabulario, con la teología paulina, nos orientan ahora a considerar más de cerca las consecuencias morales-comunitarias que la participación en la "Cena del Señor" lleva consigo, según S. Pablo.

\section{2 - Nueva Alianza, Eucaristía y moral eclesial en Pablo}

\section{a) Comunión saboteada}

Con el episodio de Ananías y Safira, mostraba Lucas que no todo era paradisíaco en las primeras comunidades cristianas. Con este aspecto problemático de la

${ }^{11}$ Ver antes: Filip 1, 27: "Perseveran en el mismo espíritu, con una sola alma (mia-i-) psyjé-i-)". 
convivencia eclesial tendrá que vérselas Pablo, muy especialmente en las directivas y amonestaciones, que dirige a "la Iglesia de Dios que residía en Corinto" ( I Cor 1,2 ).

Nos ceñiremos al corazón mismo de toda comunión cristiana, la celebración de la Eucaristía, a la que Pablo dedica todo el cap. 11 de su misiva $^{12}$.

El Apóstol encara ahora otro motivo de separatismo, que atenta al sentido mismo de la "Cena del Señor", las diferencias provenientes del diverso "status social", entre los miembros de la comunidad:

Oigo que, al reuniros en iglesia, hay entre vosotros divisiones (sjismata). Cuando os reunís, pues, en común, eso no es comer la Cena del Señor, porque cada uno come su propia cena $y$ mientras uno pasa hambre, otro se embriaga (I Cor 11, 18-20).

Las estridentes diferencias, fustigadas aquí por Pablo (embriaguez - hambre), eran debidas a la diversa extracción social de los miembros de la comunidad, que a unos permitía excesos, mientras que dejaba a otros sin lo mínimo indispensable. Se dejaban de lado las poderosas motivaciones de fe, que

\footnotetext{
${ }^{12}$ Ya adelantó el tema en 10, 14-22. Según muchos intérpretes, la consideración de la asamblea cristiana se extiende también a los tres importantes capítulos, sobre el uso de los carismas en el desarrollo de la misma (12-14). En efecto, allí emerge una vez más el tema del "Cuerpo de Cristo" $(10,17 ; 12$, 12-30).
}

apuntaban más a lo unificante, que a la segregación

Lo más disonante era que se comiera "la propia cena", siendo así que el acto era eminentemente comunitario, subrayado por la reiteración de un verbo, indicador de convergencia hacia la asamblea (iglesia): "Os reunís (syn - érjesthe) más bien para mal que para bien" (v. 17). "Al reuniros en iglesia (syn erjómenon hymón en ekklesía-i-), oigo que hay cismas entre vosotros" (v. 18). No deja de ser paradojal y escandaloso que una "reunión" termine en "división".

Pero, abundará todavía más: "Cuando os reunís en común (syn erjómenon hymón epí tó autó: reduplicación de lo unitario), no es comer la Cena del Señor" (v. 20). Por fin, casi como una inclusio, que abarca toda la reflexión: "Así, pues, hermanos míos, cuando os reunís en común (syn - erjómenoi) para comer, esperaos unos a otros. Si alguno tiene hambre, que coma en su casa, a fin de que no os reunáis (hina me...synérjesthe) para el castigo" (vv. 33-34).

Aquellas congregaciones terminaban en un mero conglomerado, sin lazos humanos y menos "cristianos", puestos en juego. Habiendo sido convocados a "cenar unos con otros", prácticamente "comían unos sin los otros". 


\section{b) Clasismos en pugna con la Nueva Alianza}

Pero, por encima de todo, las comidas cristianas no tenían por fin organizar un mero agasajo de camaradería, sino conmemorar la "Cena del Señor", que entrega su "cuerpo por vosotros" (v. 24).

La estridencia entre la liturgia y los banquetes tan poco solidarios, que la precedían en Corinto, evoca inmediatamente en Pablo las notables consecuencias éticas que lleva siempre consigo la comunicación con el Señor, allí presente. ¿Cómo aspirar a una "cena propia" (v. 21), cuando se trata de actualizar la entrega hasta la muerte del Señor Jesús, que, dando su sangre a beber, como pacto nuevo, indica tan claramente el repudio de todo egoísmo?

Las palmarias diferencias (en tiempo ${ }^{13}$, espacio y calidad de platos, todas debidas a la distancia entre estratos sociales), no condecían con la Cena Eucarística, acto que, al revés, sostenía y consagraba la superación de todo separatismo, que atentara contra la estrecha unidad, ya iniciada en el bautismo ${ }^{14}$ y alimentada

\footnotetext{
${ }^{13}$ Pablo detalla que cada uno "se adelanta (pro - lambánei) a comer su propia cena" (v. 21). Los cristianos libres y acomodados, tenían tiempo a disposición. Los esclavos, estaban más sujetos a cumplir con sus horas de trabajo. Podría verse ahí una causa de que los pobres se encontraran con espectáculos no muy edificantes, cuando llegaban necesariamente más tarde a la casa, donde se celebraría la Eucaristía.

${ }^{14}$ Ver Gal 3, 27-28.
}

frecuentemente (osákis) "hasta que él vuelva" (v. 26). En semejantes condiciones no hay Eucaristía posible (v. 20) y todo se distorsiona, ya que se estima más la propia comodidad que la "Iglesia de Dios", no compuesta de selectos aristócratas, sino también de "los que no tienen nada" (v. 22).

La celebración de la Nueva Alianza (v. 25), caracterizada por su eficacia sobrehumana en los corazones $^{15}$, ha de compenetrarse con toda la vida, si no se la quiere desvirtuar en una farsa. El sacramento posee una proyección moral, que abraza toda la vida.

Por eso, se ha de distinguir bien la causa de la culpabilidad de los corintios. No abusaban de la Eucaristía en el sentido de profanación, como si no hubieran caído en la cuenta de que se trataba de una acción sagrada. Su responsabilidad residía en que no valoraban las implicaciones comunitarias de su encuentro con Cristo, porque, en último término no se lo valora a EL, si se desestima al prójimo, misteriosamente unido con EL.

Prácticamente estaban despojando de su "novedad" a la alianza ofrecida por el Señor Jesús, para volver a aprisionarla en los viejos y rígidos moldes económicos del paganismo.

\footnotetext{
15 Ver: Jer 31, 31-34; Ez 36, 26-28. Es el mismo Dios, quien "pone su ley o espíritu" en corazones pétreos, que así se vuelven "de carne".
} 
También se puede vislumbrar un malentendido "sacramentalismo". Es decir, apreciaban la Eucaristía, puesto que seguían acudiendo a ella, pero parece que, para algunos, se había convertido en un talismán, que salva o santifica independientemente del esfuerzo por sintonizar, con las necesarias consecuencias prácticas y morales de lo que se vive en los ritos.

\section{c) Intolerable incoherencia con la voluntad de Cristo}

Es que, Jesús, al dejar su Eucaristía a la Iglesia, se entregó a sí mismo, fijando así el sentido de su pasión y resurrección. No legó sólo doctrina o normas, sino que, por su amor extremo, transfiguró en factor potentísimo de unidad al acto más significativo de la disgregación total: la muerte. Las palabras de la institución: "Este cáliz es la Nueva Alianza que se sella con mi sangre. Siempre que la beban, háganlo en memoria mía" (v. 25), transforman en sustancia nutritiva, que da vida, "la sangre derramada", o sea la muerte misma, no ya encarada como un desenlace fatal, sino como "memoria" de un ajusticiado, que "volverá", porque, a partir de la "noche en que fue entregado" (v. 23), el que fue juzgado, ha sido constituido como quien "nos juzga... para que no seamos condenados con el mundo" (v. 32).

El gesto sacramental expresa de una manera gráfica la eficacia comunitaria del sacrificio. Jesús se convierte en comida y bebida para todos los hombres. Su entrega, por tanto, no sólo lo hace agradable a Dios, sino que también la forma en que es significado y realizado, señala, a su vez, el beneficio para nosotros, ya que nos pone en estrecha comunión con EL y por su medio con Dios.

La anterior convivencia de los apóstoles con Jesús, incluso la participación en comidas tan portentosas, como fue la ofrecida en "lugar descampado" (Mt 14, 15), no daban todavía el toque propio de este banquete de la "Nueva Alianza", donde el propio Jesús se vuelve alimento, haciendo realidad aquel aspecto subrayado por Jeremías: la actividad de Dios, que transformaría a los hombres desde dentro (Jer 31, 33).

Pero, tal actividad divina no está reservada a un grupo de élite, sino que sitúa en íntima comunión recíproca a todos los convocados. Se trata de una comida compartida, sin excluir a nadie, puesto que el cuerpo "se entrega por vosotros" y la sangre "es derramada (también) porvosotros" (LC 22, 19 y 20; I Cor 11, 24).

El banquete eucarístico no es el resultado de solas convergencias horizontales, sino que tiene su origen en la convocatoria de Cristo, que entrega su sangre "por todos", obteniendo lo que nadie, ni siquiera en conjunto, podría haber logrado: "El perdón de los pecados" (Jer 31, 34 ; Mt 26, 28).

Tan descollante para la fe era esta veta profunda de la Cena del 
Señor, que el mismo Pablo, respetando siempre la dualidad de los elementos eucarísticos (I Cor 10, 16), polarizado por la realidad tan compacta, que crea el sacramento, a un momento dado, espontáneamente pasa a fijarse en uno solo de ellos.

Ya que hay un solo pan, todos nosotros, aunque somos muchos, formamos un solo cuerpo, porque participamos de ese único pan (I Cor 10,17$)^{16}$.

Ese único cuerpo es la Iglesia. Si del pan eucarístico dijo el Señor: "Esto es mi cuerpo" (v. 24), de los corintios declara Pablo: "Vosotros sois el cuerpo de Cristo" $(12,27)$. Una cosa no va sin la otra y separarlas "no es comer la Cena del Señor". Los corintios, segregando a algunos, en un trato desigual, estaban quebrantando el mismo Cuerpo del Señor, que no admite amputaciones.

Estas dimensiones de la Alianza no se manifestaron en el Calvario. Allí Jesús está solo, sus discípulos lo han abandonado. Sin la Eucaristía, por tanto, la revelación sería incompleta y el sacrificio de Cristo no desplegaría su maravillosa eficacia. La Cena del Señor mancomuna lo disperso, haciendo de la misma traición instrumento de comunión. Porque, impresiona verdaderamente que "en la noche en

16 En forma análoga, al sacar sus conclusiones finales $(11,29)$, el esquema bipolar, se rompe en el centro de la frase, aunque inmediatamente antes y a renglón seguido, sea restablecido: "El que come y bebe sin discernir el CUERPO, come y bebe su propia condenación".

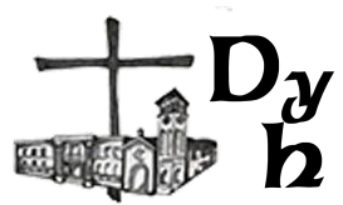

que fue entregado", Jesús "diera gracias" (I Cor 11, 23), transportándose, por encima de su drama personal, hacia las futuras generaciones, que participarían de esta Alianza: "Cada vez que la bebáis, hacedlo en memoria mía" (v. 25).

Ahora bien, conectarse con semejante generosidad sin límites, para después atrincherarse en cotos cerrados y aristocráticos, no condice con lo que se conmemora, resulta una chirriante estridencia.

\section{d) La Cena del Señor: remedio eficaz contra el cisma}

Pese a toda la severidad de sus reproches, se ha de notar que Pablo no declara una "huelga de Eucaristía". Pues, si se dejara de celebrar hasta que las comunidades eclesiales se sientan acordes con la unidad y ausencia de pecado en esta historia, no se podría renovar el mandato de Cristo hasta la Parusía. El mismo Pablo entrelaza las dos realidades: "Es necesario que haya herejías, para que se hagan manifiestos entre vosotros los que son probados" $(11,19)$. La Eucaristía, por fallas que haya en la comunidad, será constantemente un reclamo, un espoleo, para no instalarse en esa situación. Por eso el Apóstol la ve también como una ocasión para que "se examine el hombre" (v. 28). Así vamos siendo juzgados por Dios, 
para no ser condenados con este mundo (vv. 31-32) ${ }^{17}$.

Por lo demás, en la misma primera Eucaristía, celebrada por el mismo Jesús, se vio precisado a corregir los defectos de los suyos: "Se produjo entre ellos una discusión, a ver cuál de entre ellos era el más grande" (LC 22, 24). Ni más ni menos que como en Corinto. Pedro se empecinó en saber más que su Maestro, cuando le predijo su cobarde traición. No entienden casi nada de lo que les anuncia (ver: LC 22, 35-38; Jn 13, 7-8; 14, 8-9). Los dos caminantes de Emaús estaban todavía enredados con ensueños de mesianismo político (Lc 24, 18-23), lo cual no fue óbice para que Jesús les explicara las Escrituras y se les diera a conocer en "la fracción del pan" (vv. 30-31.35).

\section{e) No dividir el Cuerpo de Cristo}

De pasada, hemos advertido hasta qué punto asocia Pablo la estrecha cohesión creada por la Cena del Señor entre quienes se nutren de la misma. Se le presenta con toda evidencia la comunidad, no como el resultado de un contrato social, sino como la articulación de los miembros de un organismo vivo (I Cor 10, 16-

\footnotetext{
17 Esta faceta evoca inmediatamente otra secuela moral intracristiana, con grandes alcances para la evangelización (Jn 17, 21): la dolorosa situación de ausencia de "comunión" entre las iglesia y confesiones, que celebramos por separado el sacramento de la unidad.
}

17; ver ya: 6,15$)^{18}$. Si este "Cuerpo de Cristo" nace con el bautismo (ver: ibid., 12, 13), su constante mantenimiento se nutre de la Eucaristía. De ahí también se explica la fuerte reacción de Pablo, no bien se entera de las "divisiones" (sjísmata), que se producen en Corinto, precisamente al celebrar el acontecimiento que está apuntando a todo lo contrario: la armonía capaz de integrar lo plural en lo único.

Dado que Cristo no es un miembro más, sino la fuente, el corazón, que precede e incorpora a todo el resto, EL mismo es quien actualiza y sostiene la interacción vital entre los miembros por medio de la presencia eficaz de su "Cena".

De ahí que intentar desarticular esta íntima reciprocidad, cediendo a tratos diferenciados de unos y otros, debidos a la diversa extracción social de los comensales, no sólo sea contraproducente en el ámbito funcional (que también lo es) ${ }^{19}$, sino que, por encima de todo, con un mayúsculo sinsentido, descuartiza lo que Cristo quiere amalgamar muy estrechamente en su cuerpo y su sangre.

El Apóstol no se pliega a soluciones engañosas, una de las

\footnotetext{
${ }^{18}$ Las consecuencias plenas de esta realidad serán explicitadas por Pablo especialmente en los capítulos 12 al 14 de esta misma carta y en Colosenses y Efesios.

${ }^{19}$ Aún desde un punto de vista solamente racional se entiende que, "la unión hace la fuerza" y que, al contrario, "todo reino dividido va a su ruina" $(M c 3,24)$. Pero Pablo apunta a mayores profundidades.
} 
cuales podría ser el fomento de "pequeñas comunidades", en las que, por razones de cultura, semejante estamento social o simpatía, fuera más fácil el mutuo entendimiento. Él, basado en la naturaleza misma de lo que se celebra, aspira a una "fraternidad" entre diferentes clases. En caso que surjan "herejías", tampoco cederá en busca de una romántica armonía, sino que las considerará como ocasión de fortificación de los de "probada virtud" (ibid., 11, 19). La Eucaristía en comunidades demasiado reservadas no las entrenará para acoger a los pecadores. Más acogedoras son las que reciben a todo tipo de gente. En celebraciones masivas no se experimentará la confianza de familia o de vecinos, pero dar la paz a un extraño, sin averiguar qué tipo de persona es, nos acerca más a la sangre de Cristo esparcida "por muchos" (Mt 26, 28).

\section{f) ¿Hay diferencia entre la primera y la "Nueva" Alianza?}

Si Jeremías y Ezequiel ponían tanto de relieve la intervención del mismo Dios para la transformación del hombre interior ("mi ley - o "espíritu" - en el corazón" -"todos enseñados por Dios": Jer 31, 33.34; Ez 36, 27), con todo, no indicaban por qué medio concreto se llevaría a cabo este "transplante de corazón". Ahora, Jesús lo ha indicado en "el cáliz de mi sangre en la Nueva Alianza" (I Cor 11, 25; LC 22, 20).

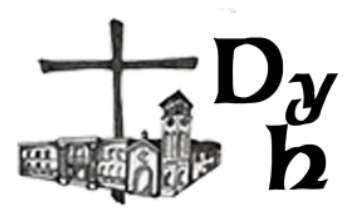

¿Cómo es, entonces, que Pablo tiene que intervenir tan enérgicamente, no sólo "aleccionando una vez más", a quienes participan de la "Nueva Alianza", sino debiendo regañarlos, porque están caminando en dirección diametralmente opuesta?

Los datos completos del Nuevo Testamento nos enseñan que, si Dios actúa, aún en un pacto que no podrá ser superado por ningún otro en adelante $^{20}$, no lo hace, prescindiendo del hombre ${ }^{21}$. También nos informan sobre los impedimentos que puede encontrar la acción del Espíritu en el corazón humano, "porque la carne desea contra el espíritu" (Gal 5, 17). Ya Ezequiel (36, 27) formulaba esta coordinación: "Haré que caminéis en mis

20 La alianza vaticinada por Jeremías y cumplida en Cristo no es "nueva" en el sentido de néa, o sea: "una más", restauración de la antigua, sino con el matiz de kainé, señalando una calidad distinta, que antes no existía. Así Jesús (Mt 26, 29) anuncia en la última cena que no volverá a tomar vino hasta que lo beba "nuevo" (kainón) en el reino de Dios. Indica, no ya un vino terrenal, sino celestial y escatológico.

${ }^{21}$ Lo daba a entender Pablo en su primer escrito, cuando comprobaba la Nueva Alianza en acto, porque los tesalonicenses eran efectivamente Theodidaktói (enseñados por Dios) en el amor fraterno (I Tes 4, 9). Cosa que no lo inhibía, para aportar simultáneamente sus advertencias y correcciones. Es que Dios "enseña" íntimamente, pero no por eso prescinde de los maestros externos, enviados por su mismo Hijo: "El Señor le tocó el corazón (a Lidia), para que aceptara las palabras de Pablo" (Hech 16, 14). 
preceptos" 22 . Sin "carburante" (=Dios en el corazón), no puede moverse un coche, pero tampoco sin el conductor.

Ahora bien, nada más significativo y efectivo de esta "intimidad de Dios" que la "Nueva Alianza en la sangre de Cristo". Semejante acercamiento de Dios ha de estar por encima de cualquier alejamiento causado por separatismos clasistas. Estaba en juego un punto neurálgico de la vida eclesial, porque cuando se distorsiona la Cena del Señor, decae la fe y su deterioro se manifiesta en la conducta inmoral, generadora de sectas y división en el Cuerpo de Cristo. Se desvirtúa la médula vital de la comunidad "toda vezquecoman y beban indignamente... hasta que vuelva el Señor" (ver: I Cor $11,26$ y 27$)$.

También los profetas
fustigaron el divorcio entre suntuosas ceremonias y la vida (Is 1 , 11-17: Jer 7, 1-7), pero la reprimenda paulina se diferencia en que ya no se puede esperar otra alianza más. La establecida por la sangre de Jesús es la última, "hasta que El vuelva" (v. 26) ${ }^{23}$.

La intervención de Dios, pues, no significa que se suprima el trabajo, por momentos arduo, del ser humano. Hasta Jesús, dador del

\footnotetext{
${ }^{22}$ La LXX acentúa la colaboración divino humana, al reduplicar el mismo verbo: "Poiéso hina...poiésete" (=haré que hagáis).

23 Abundará en la "definitividad" de la alianza en Cristo el autor de Hebreos (1, 1-4; $8,6-13 ; 9,15-28)$.
}

Espíritu $^{24}$, y, por ende, posesor del mismo, no se vio privado de penosa lucha, para llevar a término su obra de redención. El apunte paulino de "la noche en que fue entregado" (I Cor 11,23) no insiste en la tragedia vivida por Jesús, pero, dado que se remite a lo que "ha recibido" (v. 23), sin hacer violencia al texto, podemos reconstruirla con los datos unánimes, que nos brindan otros escritos del Nuevo Testamento ${ }^{25}$. Esta conducta de Jesús ha de inspirar a quienes "en su sangre", se vuelven partícipes de la "Nueva Alianza"26.

Por eso la deplorable coyuntura en Corinto no desemboca en una renuncia fatalista a los encuentros eucarísticos, sino que, pese a su defectuosa celebración, se la valora como oportunidad única para evaluar la conciencia, ya personal ya comunitaria y formular el "imperativo" de los necesarios cambios (vv. 28-34), para que se permita al "indicativo" de la fuerza divina, actuante en la Nueva Alianza, desplegar su obra de unidad en el Cuerpo de Cristo $^{27}$.

Salvo empecinada cerrazón individualista o grupal, la

\footnotetext{
24 "El Espíritu" es "de Cristo" (Rom 8, 9; Filip $1,19)$.

${ }^{25}$ Mc 14, 33.24 y par. Lc 22, 44; Jn 12, 27-28; Hebr 5, 7-8.

26 "Cristo padeció a fin de que sigáis sus huellas" (I Ped 2, 21).

${ }^{27}$ Nos referimos al "hecho" objetivo debido sólo a la acción divina (indicativo), que, sin embargo, no actúa, si se le ponen impedimentos y no se colabora con él. En definitiva: el opus operatum, que implica no menos el opus operantis.
} 
participación en la Eucaristía será siempre la más fuerte llamada a la conversión, el mejor modo de revitalizar la alianza renovadora de vida y costumbres en la Iglesia y a partir de ella en el mundo.

\section{3 - Conclusión}

Tanto Lucas, con la "koinonía", no sólo resultado de "amistad" u otros valores, que ayudan siempre, pero no son "fundantes" en Cristo, como Pablo con la "Nueva Alianza en la sangre de Cristo", excluyentes de cualquier tipo de segregación, sobre todo si proviene de la más opuesta al Evangelio y a toda la Biblia, aquella que mira sólo a la posición acomodada o menesterosa en la sociedad, patentizan los alcances de moral comunitaria que engendra la participación en la misma fe.

Tomás puede decir: "Señor mío y Dios mío" sólo después de haberse reintegrado al resto de los discípulos, provocando asimismo la bienaventuranza para "todo" el que "cree": "Felices los que creen sin haber visto" (Jn 20, 26-27).

\section{Bibliografía}

Aristóteles (1995): Ética nicomáquea, Planeta DeAgostini - Gredos, Madrid.

Diógenes Laercio (1945): Vidas, opiniones y sentencias de los filósofos más ilustres, tomo 2, Emecé Editores, Buenos Aires.

Juan Pablo II (1982), Discurso
inaugural de la III' Conferencia
General del Episcopado
Latinoamericano [Puebla, 28/
01/1979], en: Puebla - Comunión y
participación, BAC, Madrid.

